\title{
Determination of future prevention strategies in elite track and field: analysis of Daegu 2011 IAAF Championships injuries and illnesses surveillance
}

\author{
Juan-Manuel Alonso, 1,2 Pascal Edouard, 3,4 Giuseppe Fischetto, 1,5 Bob Adams, 1,6 \\ Frédéric Depiesse, ${ }^{1,4}$ Margo Mountjoy ${ }^{7-9}$
}

${ }^{1}$ Medical and Anti-Doping Commission, International Association of Athletics

Federations (IAAF), Monaco 2Medical Department, Royal Spanish Athletics Federation (Real Federación Española de Atletismo, RFEA), Madrid, Spain

${ }^{3}$ Department of Clinical and Exercise Physiology, UniversityHospital of Saint-Etienne, and Laboratory of Exercise Physiology (LPE EA 4338), University of Lyon, F-42023, Saint-Etienne, France

${ }^{4}$ Medical Commission, French Athletics Federation (FFA)

Paris, France

${ }^{5}$ Medical Department, Italian Athletics Federation (FIDAL), Rome, Italy

${ }^{6}$ Sports Medicine and Science Committee, USA Track and Field, Indianapolis, Indiana, USA

${ }^{7}$ Department of Family Medicine, Michael G DeGroote School of Medicine, McMaste University, Hamilton, Canada ${ }^{8}$ Medical \& Scientific

Department, International Olympic Committee (IOC). Lausanne, Switzerland ${ }^{9}$ FINA Bureau and Sports Medicine, Fédération Internationale de Natation (FINA), Lausanne, Switzerland

\section{Correspondence to} Juan-Manuel Alonso, RFEA Servicios Médicos, Avenida de Valladolid, 81, 28008-Madrid; Spain;

dir.medico@rfea.es

Received 31 January 2012 Accepted 6 March 2012 Published Online First

20 April 2012

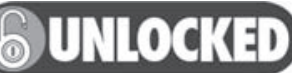

This paper is freely available online under the BMJ Journals unlocked scheme, see http:// bjsm.bmj.com/info/unlocked.dtl

\section{ABSTRACT}

Objective To determine the incidence and characteristics of newly incurred injuries and illnesses during international Athletics Championships, by improving the medical surveillance coverage, in order to determine future prevention strategies.

Design Prospective recording of newly occurred injuries and illnesses.

Setting 13th International Association of Athletics Federations World Championships in Athletics 2011 in Daegu, Korea.

Participants National team and Local Organising Committee physicians; and 1851 registered athletes.

Main outcome measures Incidence and characteristics of newly incurred injuries and illnesses. Results $82 \%$ of athletes were covered by medical teams participating with a response rate of $94 \%$. A total of 249 injuries were reported, representing an incidence of 134.5 injuries per 1000 registered athletes, and 119 $(48 \%)$ resulted in time loss from sport. A total of 185 injuries affected the lower limb (74\%). Hamstring strain was the main diagnosis and $67 \%$ resulted in absence from sport. Overuse ( $n=148 ; 59 \%)$ was the predominant cause. A total of 126 illnesses were reported, signifying an incidence of 68.1 per 1000 registered athletes. Upper respiratory tract infection was the most common reported diagnosis (18\%), followed by exerciseinduced dehydration (12\%), and gastroenteritis/diarrhoea (10\%). The highest incidences of injuries were found in combined events and middle and long-distance events, and of illness in race walking events.

Conclusion During elite Athletics World

Championships, 135 injuries, 60 time-loss injuries and 68 illnesses per 1000 registered athletes were reported. Higher risks of injuries were found in combined events and long-distance runs. Preventive interventions should focus on overuse injuries and hamstring strains, decreasing the risk of transmission of infectious diseases, appropriate event scheduling and heat acclimatisation.

\section{INTRODUCTION}

Track and field (athletics) is both a popular and global sport. Competition in top-level athletics poses risk of suffering from injuries and illnesses as our research group has already published. ${ }^{1-3}$ The protection of the athletes' health is an important task for the International Olympic Committee (IOC) and the International Association of Athletics Federations (IAAF) ${ }^{1-5}$ and systematic injury and illness surveillance has been developed during track and field events, ${ }^{12}$ in order to determine direction for injury and illness prevention following the four-stage model of van Mechelen et al. ${ }^{6}$

Injury incidence during international athletics competitions is high: $10 \%-14 \%$ of athletes incurred an injury during the Championships, and half of these were expected to result in time loss from sport. ${ }^{1-3}$ Therefore, introducing prevention strategies focused on the most relevant injuries (high frequency and/or severity), adapted to their mechanisms and risk factors, is of interest. 67

In addition, approximately $7 \%$ of athletes incurred an illness during the 2009 IAAF Championships; $50 \%$ lead to time loss from sport. ${ }^{2}$ This rate was comparable to those reported in similar top-level competitions. ${ }^{589}$ Since reduced illness rates have been reported to be associated with higher team performance during the Winter Olympic Games 2010 for the Norwegian team, ${ }^{10}$ illness-prevention strategies should be an objective for athletes, National Federations and National Olympic Committees, and is congruent with the IOC and IAAF's objective to protect athlete's health.

Therefore, in keeping with this context, the aim of this study was to improve the medical surveillance system through the identification of the incidence and characteristics of newly incurred injuries and illnesses during track and field international Championships, in order to determine future prevention strategies.

\section{METHODS}

\section{Implementation}

The present study used the methodology of injury and illness surveillance validated by the IOC, ${ }^{4}$ and implemented by the IAAF during international track and field competitions, ${ }^{12}$ during the period of the Daegu 2011 IAAF World Championships (27 August to 4 September). The research group repeated the implementation stages taken at previous surveillances and described elsewhere. 12 In addition, three volunteers from the local Organising Medical Staff participated in the data collection and helped the authors (JMA, GF, FD and BA) with daily interviews of participating team physicians, quality review of the daily reports, and data input. The issue of duplicate reporting was solved by the consensus of two authors (PE and JMA); information from the 
national team physician's report was preferred over the Local Organising Committee (LOC) physician's report.

\section{Definitions of Injury and Illness}

The study followed the injury and illness definition criteria published previously. ${ }^{1249}$

\section{Injury and illness report form}

The injury and illness report form was used in previous studies and has already been published. ${ }^{1-5}$ The injury location classification has been improved in order to distinguish anterior and posterior and/or medial and lateral location for upper and lower extremity injuries. Although this form was available in several languages, English reporting was encouraged.

\section{Confidentiality and ethical approval}

The athletes' accreditation number was used only to avoid duplicate reporting from team and LOC physicians and to provide information on age, gender and national federation of the athlete from the IAAF database. All injury and illness reports were stored in a locked filing cabinet and were made anonymous after the Championships. Confidentiality of all information was ensured so that no individual athlete or team could be identified. Ethical approval was obtained from the Oslo University School of Medicine Ethical Committee.

\section{Data analysis}

The response rate and coverage, the number of registered athletes (population at risk), competing athletes (athletes exposed to the competition) and participations (athletes' exposure in competition) were calculated using a list of athletes registered for the Championships provided by the IAAF and the competition schedule published on the internet (http://daegu2011. iaaf.org/index.html). The incidence of injury and illness were calculated in accordance with the IOC approach ${ }^{4}$ and previous track and field studies. ${ }^{1}{ }^{2}$ The gender, age ( $\leq 20$ years of age, 21-25 years, $26-30$ years, $\geq 31$ years), severity (time-loss, no time-loss), circumstance (training, competition) and type of event were analysed for risk evaluation. Statistical methods applied were means with SD and t-test for age values, and frequencies, cross-tabulations, and $\chi^{2}$-test for injury and illness data. All data were processed using excel. Significance was accepted at $\mathrm{p} \leq 0.05$.

\section{RESULTS}

\section{Coverage and response rate of the injury and illness surveillance system}

All countries with more than 15 registered athletes $(n=61$; $30.3 \%$ of 201 national teams) participated in this study covering 1512 athletes ( $81.7 \%$ of 1851 registered). Coverage and response rate are reported in table 1 . The number of injuries reported by the national medical teams was significantly higher than those reported by the LOC physicians (148/116, respectively; $\left.\chi^{2}=8.3 ; p=0.004\right)$, and the number of illnesses was similar $\left(64 / 76\right.$, respectively; $\left.\chi^{2}=2.7 ; p=0.1\right)$. Fifteen injuries and 14 illnesses were reported from both sources. Among athletes covered by national medical teams participating in this study, $27 \%$ of injuries and $24 \%$ of time-loss injuries and $26 \%$ of illnesses and $4 \%$ of time-loss illnesses were reported only by the LOC physicians and not reported by national medical teams.
Table 1 Coverage and response rate of the injury and illness surveillance system during IAAF World Athletics Championships.

\begin{tabular}{|c|c|c|c|c|c|}
\hline & Daegu 2011 & \multicolumn{2}{|c|}{ Berlin 2009² } & \multicolumn{2}{|c|}{ Osaka $2007^{1}$} \\
\hline Total number of countries & 201 & 200 & & 200 & \\
\hline $\begin{array}{l}\text { Total number of registered } \\
\text { athletes }\end{array}$ & 1851 & 1979 & & 1980 & \\
\hline $\begin{array}{l}\text { Number of medical teams } \\
\text { participating in the } \\
\text { injury and illness } \\
\text { surveillance (\%) }\end{array}$ & $61(30.3)$ & 47 & $(23.5)$ & 49 & (24.5) \\
\hline $\begin{array}{l}\text { Number of athletes } \\
\text { covered (\%) }\end{array}$ & $1512(81.7)$ & 1486 & (75.1) & 1660 & $(84.0)$ \\
\hline $\begin{array}{l}\text { Comparisons with } \\
\text { Daegu } 2011 \text { surveillance }\end{array}$ & & \multicolumn{2}{|c|}{$\chi^{2}=24.5 ; p<0.001$} & \multicolumn{2}{|c|}{$\chi^{2}=3.1 ; p=0.08$} \\
\hline $\begin{array}{l}\text { Number of report forms } \\
\text { returned (response } \\
\text { rate in \%) }\end{array}$ & $515(93.8)$ & 382 & $(90.3)$ & 333 & (76.0) \\
\hline $\begin{array}{l}\text { Comparisons with } \\
\text { Daegu } 2011 \text { surveillance }\end{array}$ & & \multicolumn{2}{|c|}{$\chi^{2}=4.1 ; p=0.04$} & \multicolumn{2}{|c|}{$\begin{array}{l}\chi^{2}=66.6 \\
p<0.001\end{array}$} \\
\hline
\end{tabular}

\section{Frequency and characteristics of injury}

A total of 249 injuries were reported, representing an incidence of 134.5 injuries per 1000 registered athletes (95\% CI 119.0 to 150.1 ), and 78.1 injuries per 1000 athlete participations (95\% CI 68.7 to 87.4) (table 2). A total of 237 injury incidents with 246 injured body parts (three cases missing location) and 248 injury types (one case missing injury type) were reported.

Affected body parts, types and injury diagnoses are reported in table 3. The lower limb was affected in $74.3 \%$ of injuries $(\mathrm{n}=185)$. The thigh was the most frequently injured ( $\mathrm{n}=67 ; 26.9 \%$ ) with posterior thigh (hamstring) involved in 58 cases (23.3\% of all injuries). The most frequent types of injury were strains ( $n=77 ; 30.9 \%)$, followed by sprains $(n=54$; $21.7 \%)$, muscle cramps $(\mathrm{n}=43 ; 17.3 \%)$ and skin laceration $(\mathrm{n}=23 ; 9.2 \%)$. The most common diagnosis was hamstring strain $(\mathrm{n}=39 ; 15.7 \%)$.

\section{Circumstance, causes and severity of injury}

Most of the injuries occurred during competition ( $\mathrm{n}=140$; $56.2 \%$; almost half during finals $(\mathrm{n}=69)$ and 40 injuries occurred during training $(16.1 \%)$. This information, however, was missing for 69 injuries $(27.7 \%)$. Injuries in competition and during training were similar with respect to injury location and proportion of time loss but significant differences were observed for injury type $\left(\chi^{2}=21.7 ; \mathrm{p}=0.001\right)$ and cause $\left(\chi^{2}=24.5 ; p=0.001\right)$, especially for overuse injuries with sudden onset (32.4 8.1 vs $3.8 \pm 2.8$ injuries per 1000 registered athletes, respectively). Injury risk during finals was significantly higher than during qualifying rounds $\left(\chi^{2}=5.9 ; p=0.02\right)$.

Overuse injuries were dominant $(n=148 ; 59.4 \%)$, with both gradual $(n=57 ; 22.9 \%)$ and sudden onset $(n=91 ; 36.5 \%)$, followed by non-contact trauma $(\mathrm{n}=31 ; 12.4 \%)$ and recurrence of previous injury $(n=23 ; 9.2 \%)$. Almost three-quarters $(n=17)$ of recurrent injuries reported required time loss from sport; up to 4 weeks for one athlete.

Information in relation to time loss after injury was available for 213 out of 249 injuries (85.5\%; missing for 36 cases). One hundred and nineteen injuries (47.6\% of all injuries) were expected to result in time loss, representing an incidence of 64.2 injuries per 1000 registered athletes (95\% CI 53.1 to 75.5 ), and 37.3 injuries per 1000 athlete participations (95\% CI 30.7 to 43.9) (table 2). The most common time-loss injury diagnosis 
Table 2 Athletes, exposure, injury and illness in different event groups

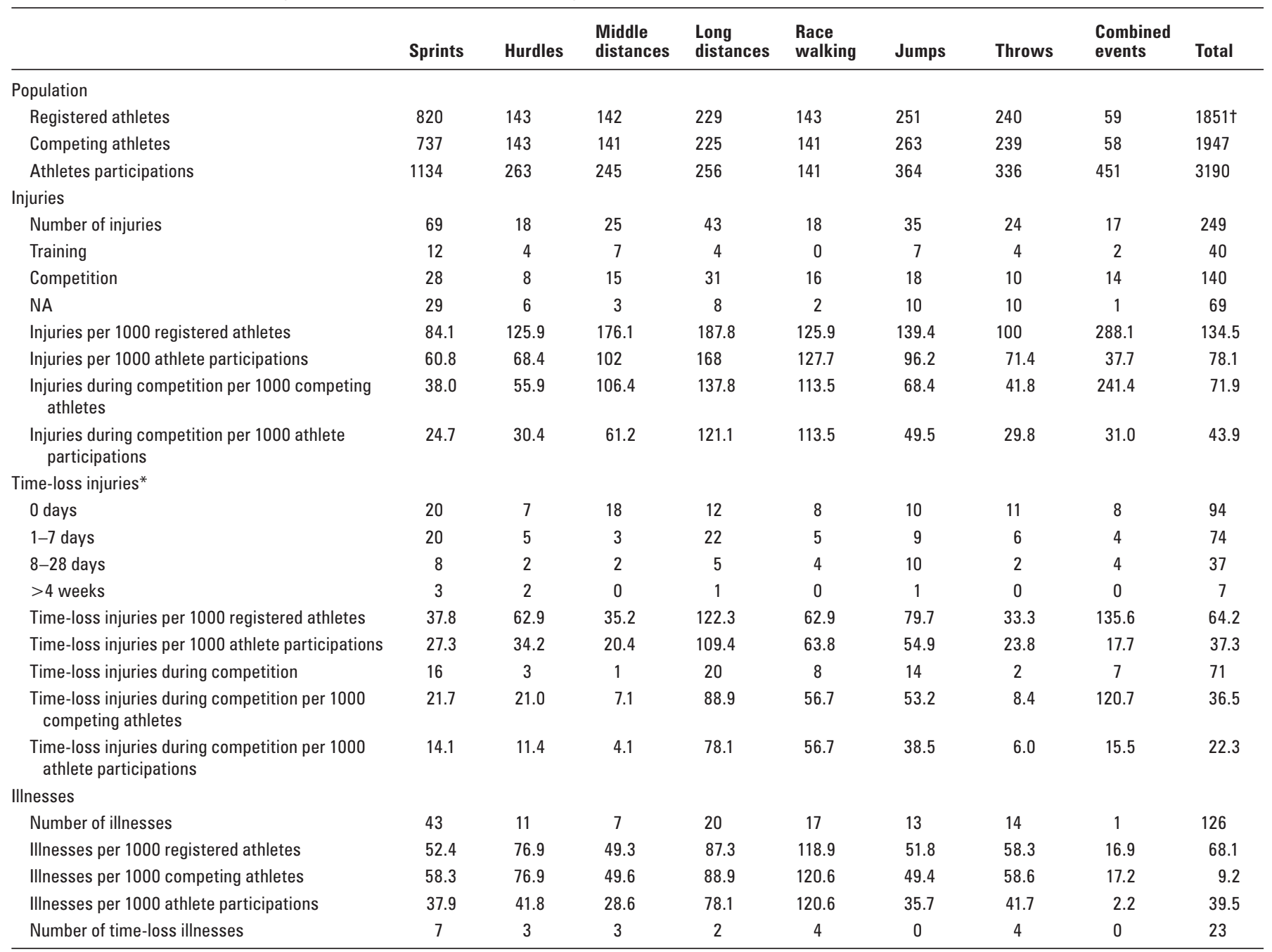

*Information on time-loss is missing for 36 injuries, for one time-loss injury the time of absence in sport was not reported.

tSince some athletes competed in more than one discipline, this is not the sum of registered athletes in each different event groups but the total number of registered athletes.

was hamstring strain ( $\mathrm{n}=18 ; 15.3 \%)$ (table 3$)$. Injuries with and without subsequent time loss differed significantly in location $\left(\chi^{2}=23.1 ; p=0.01\right)$, but not in type and cause of injury. Physician's estimations of absence from sport were reported in table 2 . The seven injuries with more than 4 weeks absence were as follows: two Achilles tendon sprains, an ankle sprain, a groin strain, a lower leg strain, a lower leg stress fracture and a thoracic spine muscle cramp. In addition, a knee anterior tendon rupture was reported, but information on duration of absence was missing for this injury.

\section{Age, sex and sport of the injured athletes}

The age of the injured athletes ranged between 17 and 42 years (mean, 26.9 \pm 4.7; missing: 4) without significant difference between males and females $(p=0.07)$. Male athletes suffered more injuries $(59.0 \%)$ than female athletes $(40.2 \%) \quad \chi^{2}=4.17$; $\mathrm{p}=0.04 ; 148.5 \pm 22.2$ vs $116.1 \pm 21.4$ per 1000 registered athletes, respectively; missing: 2), but no differences in time-loss injury and recurrence of previous injury incidences were reported. The injuries of males and females were similar regarding location, cause, severity and circumstances but differed significantly for type of injury $\left(\chi^{2}=91.5 ; \mathrm{p}<0.001\right)$; specifically for strains (28.6 \pm 7.6 vs $13.0 \pm 5.2$, respectively) and muscles cramps $(17.3 \pm 5.9$ vs $5.4 \pm 3.3$, respectively). Male athletes suffered more hamstring strain than female athletes $\left(\chi^{2}=7.7 ; p=0.006\right.$; $16.7 \pm 5.8$ vs $4.3 \pm 3$, respectively).

Most injuries occurred in athletes older than 30 years of age $\left(\chi^{2}=12.0 ; p=0.008 ; 198.4 \pm 48.8\right.$ vs $120.7 \pm 48.4,115.5 \pm 22.3$ and $130.2 \pm 26.3$ injuries per 1000 registered athletes, for younger than 20 years, 21 years to 25 years and 26 years to 30 years, respectively). The injuries differed significantly by age for location $\left(\chi^{2}=46.5 ; p=0.03\right)$ and cause $\left(\chi^{2}=21.1 ; p=0.05\right)$, but were similar regarding injury type and severity.

The incidence of injuries $\left(\chi^{2}=40.9 ; p<0.001\right)$ and time-loss injuries $\left(\chi^{2}=36.1 ; p<0.001\right)$ differed significantly between disciplines (tables 2 and 4). Athletes performing in combined events (288.1 \pm 115.5$)$, in middle- and long-distance events $(183.3 \pm 39.4)$ had the highest propensity to incur an injury, while athletes performing in combined events (135.6 \pm 87.4 ), and in long-distance events $(122.3 \pm 42.4)$ were more likely to incur a time-loss injury.

\section{Frequency and characteristics of illness}

A total of 126 illnesses were reported, equivalent to an incidence of 68.1 illnesses per 1000 registered athletes $(95 \%$ CI 56.6 to 79.5), 39.5 illnesses per 1000 athlete participations (95\% CI 32.7 to 46.3) and 7.6 illnesses per 1000 athlete days (95\% CI 6.2 to 8.9) (table 2). Affected systems, 
Table 3 Number (\%) and diagnosis of all injuries and time-loss injuries in male and female athletes

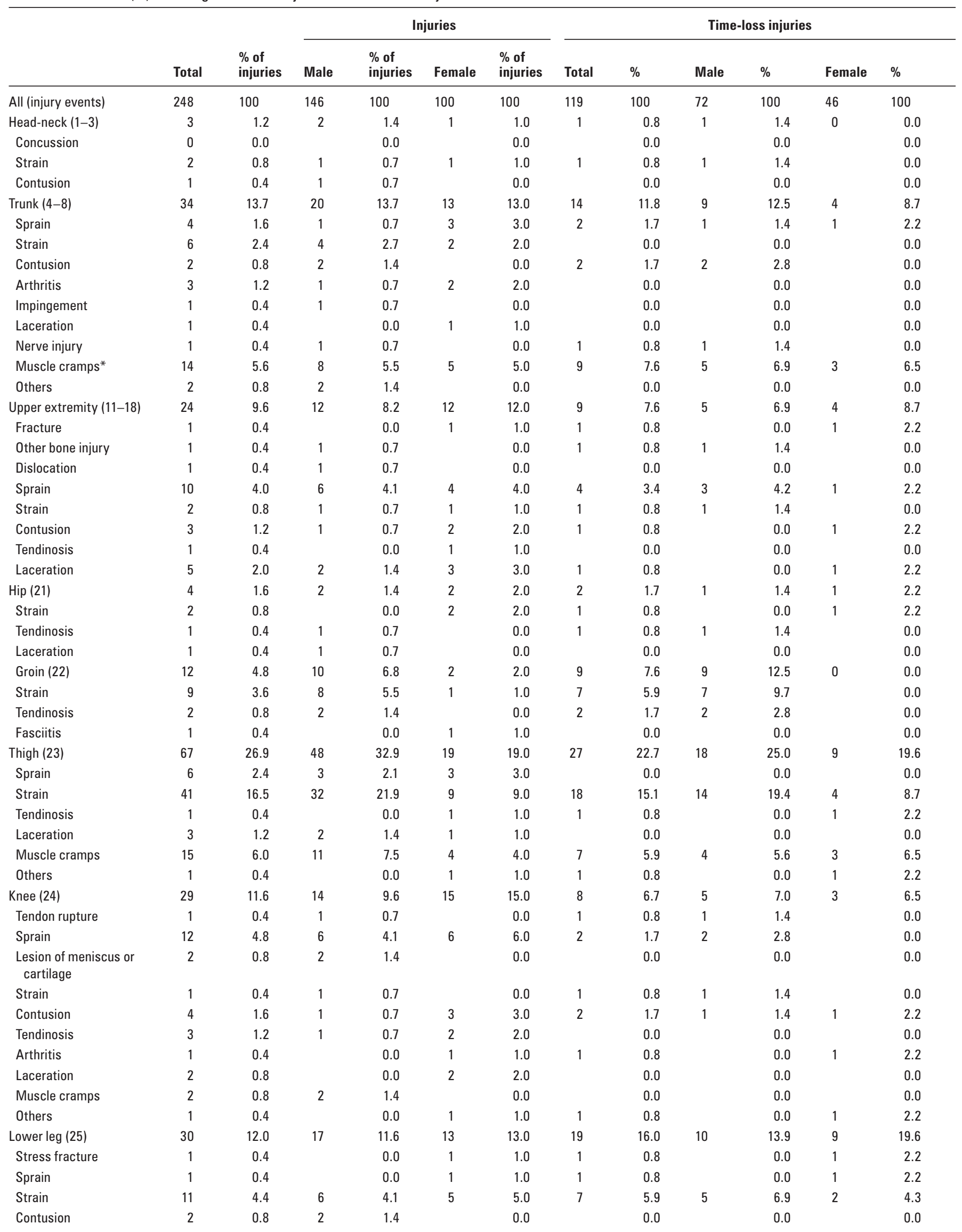




\begin{tabular}{|c|c|c|c|c|c|c|c|c|c|c|c|c|}
\hline & \multirow[b]{2}{*}{ Total } & \multirow[b]{2}{*}{$\begin{array}{l}\% \text { of } \\
\text { injuries }\end{array}$} & \multicolumn{4}{|c|}{ Injuries } & \multicolumn{6}{|c|}{ Time-loss injuries } \\
\hline & & & Male & $\begin{array}{l}\% \text { of } \\
\text { injuries }\end{array}$ & Female & $\begin{array}{l}\% \text { of } \\
\text { injuries }\end{array}$ & Total & $\%$ & Male & $\%$ & Female & $\%$ \\
\hline Sprain & 4 & 1.6 & 3 & 2.1 & 1 & 1.0 & 3 & 2.5 & 3 & 4.2 & & 0.0 \\
\hline Strain & 1 & 0.4 & & 0.0 & 1 & 1.0 & 1 & 0.8 & & 0.0 & 1 & 2.2 \\
\hline Tendinosis & 3 & 1.2 & 1 & 0.7 & 2 & 2.0 & 1 & 0.8 & & 0.0 & 1 & 2.2 \\
\hline Laceration* & 2 & 0.8 & & 0.0 & & 0.0 & & 0.0 & & 0.0 & & 0.0 \\
\hline Muscle cramps & 1 & 0.4 & 1 & 0.7 & & 0.0 & 1 & 0.8 & 1 & 1.4 & & 0.0 \\
\hline Ankle (27) & 18 & 7.2 & 8 & 5.5 & 10 & 10.0 & 14 & 11.8 & 5 & 6.9 & 9 & 19.6 \\
\hline Sprain & 15 & 6.0 & 6 & 4.2 & 9 & 9.0 & 12 & 10.1 & 4 & 5.6 & 8 & 17.4 \\
\hline Strain & 1 & 0.4 & & 0.0 & 1 & 1.0 & 1 & 0.8 & & 0.0 & 1 & 2.2 \\
\hline Contusion & 1 & 0.4 & 1 & 0.7 & & 0.0 & & 0.0 & & 0.0 & & 0.0 \\
\hline Muscle cramps & 1 & 0.4 & 1 & 0.7 & & 0.0 & 1 & 0.8 & 1 & 1.4 & & 0.0 \\
\hline Foot (28) & 15 & 6.0 & 7 & 4.8 & 8 & 8.0 & 9 & 7.6 & 4 & 5.6 & 5 & 10.9 \\
\hline Fracture & 1 & 0.4 & & 0.0 & 1 & 1.0 & & 0.0 & & 0.0 & & 0.0 \\
\hline Stress fracture & 1 & 0.4 & & 0.0 & 1 & 1.0 & & 0.0 & & 0.0 & & 0.0 \\
\hline Sprain & 1 & 0.4 & & 0.0 & 1 & 1.0 & 1 & 0.8 & & 0.0 & 1 & 2.2 \\
\hline Contusion & 5 & 2.0 & 3 & 2.1 & 2 & 2.0 & 4 & 3.4 & 2 & 2.8 & 2 & 4.3 \\
\hline Tendinosis & 1 & 0.4 & & 0.0 & 1 & 1.0 & 1 & 0.8 & & 0.0 & 1 & 2.2 \\
\hline Fasciitis & 1 & 0.4 & 1 & 0.7 & & 0.0 & & 0.0 & & 0.0 & & 0.0 \\
\hline Laceration & 3 & 1.2 & 2 & 1.4 & 1 & 1.0 & 1 & 0.8 & 1 & 1.4 & & 0.0 \\
\hline Muscle cramps & 1 & 0.4 & 1 & 0.7 & & 0.0 & 1 & 0.8 & 1 & 1.4 & & 0.0 \\
\hline Other & 1 & 0.4 & & 0.0 & 1 & 1.0 & 1 & 0.8 & & 0.0 & 1 & 2.2 \\
\hline NA & 2 & 0.8 & 1 & 0.7 & 1 & 1.0 & 1 & 0.8 & 1 & 1.4 & 0 & 0.0 \\
\hline Sprain & 1 & 0.4 & 1 & 0.7 & & 0.0 & & 0.0 & & 0.0 & & 0.0 \\
\hline Strain & 1 & 0.4 & & 0.0 & 1 & 1.0 & & 0.0 & & 0.0 & & 0.0 \\
\hline Muscle cramps & 1 & 0.4 & 1 & 0.7 & & 0.0 & 1 & 0.8 & 1 & 1.4 & & 0.0 \\
\hline
\end{tabular}

*Information on gender is missing for two injuries and for one time-loss injury; and on location is missing for two injuries.

Information on time-loss is missing for 36 injuries, for one time-loss injury the time of absence in sport was not reported

main symptoms and main diagnoses are reported in table 5. More than a third of the illnesses affected the respiratory and ear, nose, throat tract ( $n=49 ; 38.9 \%)$. In $19.0 \%$ of the cases, the affected system of illness was classified as 'other'; information was missing in one case. The most commonly reported symptom was pain ( $\mathrm{n}=39 ; 28.5 \%)$; eight symptoms were missing and 19\% were reported as 'other'. No episodes of cardiovascular-related collapses and syncope were recorded; only two illnesses affected the cardiovascular system as heat exhaustion. The most commonly reported cause was infection ( $n=12 ; 27.8 \%)$, followed by exercise induced $(n=22 ; 17.5 \%)$ and environmental $(n=17 ; 13.5 \%) ; 10$ causes of illnesses were missing and $27.0 \%$ were reported as 'other'. Upper respiratory tract infection was the most commonly reported diagnosis ( $n=23 ; 18.4 \%$ ), followed by exercise-induced dehydration ( $\mathrm{n}=15 ; 12 \%)$, and gastroenteritis/diarrhoea ( $n=13 ; 9.5 \%)$.

Twenty-three illnesses (18.3\%) were expected to result in time loss, equivalent to an incidence of 12.4 illnesses per 1000 registered athletes (95\% CI 7.4 to 17.5 ) and 7.2 illnesses per 1000 athlete participations (95\% CI 4.3 to 10.1). Gastroenteritis/diarrhoea was the most commonly reported diagnosis ( $n=6 ; 26.1 \%$ ), followed by upper respiratory tract infection $(n=5 ; 21.7 \%)$ and exercise-induced dehydration $(n=4 ; 17.4 \%)$ (table 5). Illnesses with and without subsequent time loss differed significantly in affected system $\left(\chi^{2}=18.5\right.$; $\mathrm{p}=0.02)$ and in main symptoms $\left(\chi^{2}=111.3 ; \mathrm{p}<0.001\right)$, but not in cause of illness.

No differences in illness and time-loss illness incidence were reported between male and female athletes. The illnesses of males and females were similar regarding affected system, cause, and severity of injury, but differed significantly for main symptoms $\left(\chi^{2}=21.9 ; p=0.001\right)$. The illnesses were similar between different categories of age regarding the incidence, affected systems, main symptoms, causes and severity of illnesses.

Illness incidence differed significantly between disciplines $\left(\chi^{2}=15.2 ; p=0.03\right)$, but not the incidence of time-loss illnesses $\left(\chi^{2}=10.8 ; p=0.15\right)$ (tables 2 and 6). Athletes performing in race walking $(118.9 \pm 53.0)$ had the highest propensity to incur an illness.

\section{DISCUSSION}

This study aimed, by improving the medical surveillance coverage, to improve the medical surveillance system through the identification of the incidence and characteristics of newly incurred injuries and illnesses during track and field international Championships in order to prioritise strategies for injury and illness prevention. This was the third injury and the second illness survey during IAAF World track and field Championships.

\section{Data-collection procedures}

Medical team participation during Daegu 2011 Championships was similar to Osaka $2007^{1}$ and higher than during Berlin 2009; ${ }^{2}$ the response rate was higher than during Osaka $2007^{1}$ and Berlin $2009^{2}$ (table 1). These results are consistent with our aim to improve medical surveillance coverage, which can be further improved in future studies to achieve higher compliance rates similar to those from other international events. ${ }^{38}$ Moreover, the report form was completed with few 
Table 4 Number of registered athletes, injuries and injury risk of different events

\begin{tabular}{|c|c|c|c|c|c|c|c|c|c|c|}
\hline & \multicolumn{2}{|c|}{$\begin{array}{l}\text { No. of registered athletes } \\
\text { per discipline }\end{array}$} & \multicolumn{2}{|c|}{$\begin{array}{l}\text { No. of injuries per } \\
\text { discipline }\end{array}$} & \multicolumn{2}{|c|}{$\begin{array}{l}\text { No. of time-loss } \\
\text { injuries per discipline }\end{array}$} & \multicolumn{2}{|c|}{$\begin{array}{l}\text { Injury per } 1000 \\
\text { registered athletes }\end{array}$} & \multicolumn{2}{|c|}{$\begin{array}{l}\text { Time-loss injuries per } \\
1000 \text { registered athletes }\end{array}$} \\
\hline & Men & Women & Men & Women & Men & Women & Men & Women & Men & Women \\
\hline $100 \mathrm{~m}$ & 75 & 74 & 11 & 3 & 4 & 0 & 146.7 & 40.5 & 53.3 & 0 \\
\hline $200 \mathrm{~m}$ & 55 & 41 & 7 & 2 & 2 & 1 & 127.3 & 48.8 & 36.4 & 24.4 \\
\hline $4 \times 100$ m relay & 118 & 111 & 4 & 10 & 3 & 3 & 33.9 & 90.1 & 25.4 & 27.0 \\
\hline $4 \times 400$ m relay & 87 & 100 & 8 & 8 & 4 & 6 & 92.2 & 80.0 & 46.6 & 60.0 \\
\hline $110 \mathrm{~m} / 100 \mathrm{~m}$ hurdles & 32 & 39 & 4 & 8 & 2 & 5 & 125.0 & 205.1 & 62.5 & 128.2 \\
\hline 400 m hurdles* & 34 & 38 & 2 & 3 & 1 & 1 & 58.8 & 78.9 & 29.4 & 26.3 \\
\hline $10000 \mathrm{~m}$ & 21 & 19 & 2 & 1 & 1 & 1 & 95.2 & 52.6 & 47.6 & 52.6 \\
\hline Marathon & 68 & 56 & 16 & 12 & 15 & 3 & 235.3 & 214.3 & 220.6 & 53.6 \\
\hline $20 \mathrm{~km}$ walk & 47 & 50 & 9 & 3 & 1 & 2 & 191.5 & 60.0 & 21.3 & 40.0 \\
\hline $50 \mathrm{~km}$ walk & 46 & - & 6 & - & 6 & 0 & 130.4 & - & 130.4 & - \\
\hline Discus throw & 33 & 24 & 4 & 1 & 1 & 1 & 121.2 & 41.7 & 30.3 & 41.7 \\
\hline Hammer throw & 35 & 30 & 4 & 1 & 2 & 0 & 114.3 & 33.3 & 57.1 & 0 \\
\hline Javelin throw* & 37 & 28 & 7 & 5 & 3 & 0 & 189.2 & 178.6 & 81.1 & 0 \\
\hline Shot put & 28 & 25 & 0 & 1 & 0 & 0 & 0 & 40.0 & 0 & 0 \\
\hline High jump & 19 & 29 & 2 & 4 & 1 & 3 & 105.3 & 137.9 & 52.6 & 103.4 \\
\hline Pole vault & 29 & 35 & 8 & 5 & 3 & 3 & 275.9 & 142.9 & 103.4 & 85.7 \\
\hline
\end{tabular}

*Information on gender is missing for two injuries (one in $400 \mathrm{~m}$ hurdles and one in javelin throw).

tSince some athletes competed in more than one discipline, this is not the sum of individual athletes.

missing values, suggesting that the injury surveillance system is comprehensive and convenient. However, despite the encouraging response rate from the team physicians, the quality and completeness of the reported data still remains unknown. Indeed, Florenes et a $l^{11}$ and Bjorneboe et al ${ }^{12}$ reported that prospective surveillance medical staff underestimated $39 \%$ and $19 \%$ of injuries and time-loss injuries, respectively. In our study, $27 \%$ of injuries, $24 \%$ of time-loss injuries and $26 \%$ of illnesses were underestimated by the national medical teams. Thus, other tools should be used to improve the completeness of data (retrospective interview of athletes, media monitoring or web-based system). ${ }^{12}$ Further studies are needed to determine the accuracy of this system in track and field events.

\section{Incidence and diagnosis of injuries}

The injury incidence during the Daegu 2011 Championships was almost equal to that reported during the Berlin 2009 Championships $^{2}$ (134.5 and 135.4 injuries per 1000 registered athletes, respectively). These results suggest that the injury incidence during Osaka 2007, which was the first experience of surveillance, was probably underestimated. ${ }^{1}$ Using data from the last four international Athletics events, ${ }^{1-3}$ the estimated injury incidence during elite Athletics Championships is 119.6 injuries per 1000 registered athletes (95\% CI 112.5 to 126.8), although 135 injuries per 1000 registered athletes appeared to be a realistic injury incidence.

The time-loss injury incidence during Daegu 2011 (64.3\% of registered athletes) was higher than during Berlin 2009 (46.5\% of registered athletes; $\left.\chi^{2}=5.8 ; p=0.02\right)^{2}$ and similar to during Osaka 2007 (53\%). ${ }^{1}$ Using data from the last four international Athletics events, ${ }^{1-3}$ estimated time-loss injury incidence during elite Athletics Championships is 59.3 injuries per 1000 registered athletes (95\% CI 54.1 to 64.5) and represents half of all injuries.

During elite Athletics Championships, male athletes suffered more injuries than female athletes. ${ }^{12}$ The influence of age on injury risk remains unclear; during Berlin 2009, most injuries occurred to athletes between 26 and 30 years of age, ${ }^{2}$ and during Daegu 2011 to athletes more than 30 years of age.

The circumstances of injury during elite Athletics Championships revealed that most injuries occurred during competition (56.2\% to $85.9 \%) .{ }^{1} 2$ These findings are consistent with the fact that during Championships, most of the time 
Table 5 Number (\%) and diagnosis of all illnesses and time-loss illnesses in male and female athletes

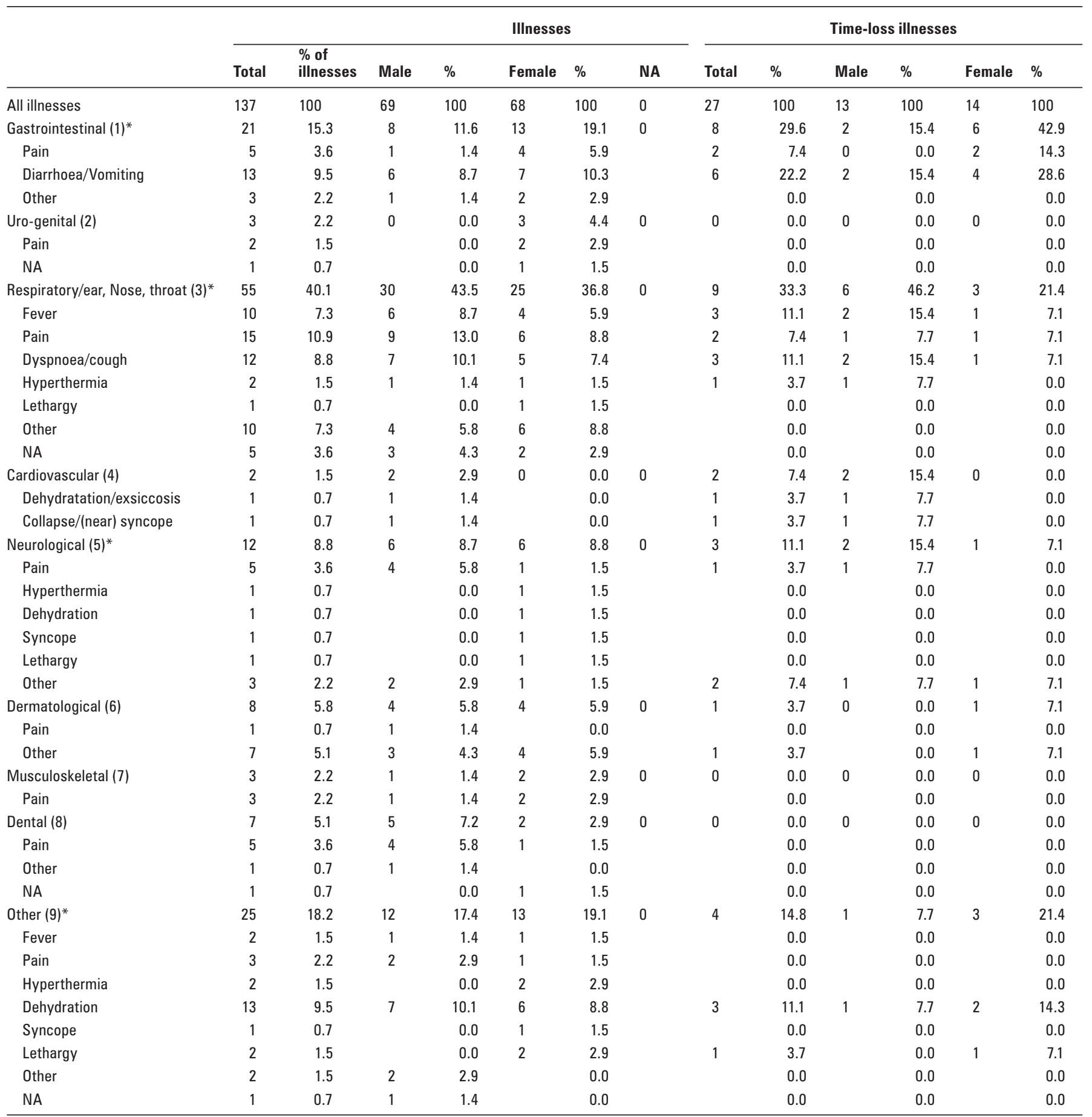

*Since some illnesses presented more than one symptom, the sum of illness and time-loss illnesses is higher than actually reported.

is spent in competition compared with the entire track and field season during which, most of the time is spent in training. 1314

The risk of injury varied substantially between the disciplines with athletes competing in combined events, steeplechase and middle- and long-distance runs having the highest risk. ${ }^{12}$ In these events, although the intensity of exercise is lower than during other events, the time spent in training and/or in competition is longer. Overuse also might have a facilitating influence in these events more than in others. This higher injury and time-loss injury risk in combined events is consistent with results of previous studies. 121516 This finding may be explained by the number and intensity of the events and the high demand from both physical and psychological standpoints. ${ }^{15-17}$ Therefore, the biomechanical and/or metabolic demands of these events need to be better understood to direct strategies for injury prevention.

During elite Athletics Championships, the most common diagnosis was thigh strain (14-17\%), and especially hamstring strain (16\%); $46 \%$ of them leading to time loss from sport. Changes in the reporting system allowed us to 
Table 6 Number of registered athletes, illnesses and illness risk of different events

\begin{tabular}{|c|c|c|c|c|c|c|c|c|c|c|}
\hline & \multicolumn{2}{|c|}{$\begin{array}{l}\text { No. of registered athletes } \\
\text { per discipline }\end{array}$} & \multicolumn{2}{|c|}{$\begin{array}{l}\text { No. of illnesses per } \\
\text { discipline }\end{array}$} & \multicolumn{2}{|c|}{$\begin{array}{l}\text { No. of time-loss illnesses } \\
\text { per discipline }\end{array}$} & \multicolumn{2}{|c|}{$\begin{array}{l}\text { Illnesses per } 1000 \\
\text { registered athletes }\end{array}$} & \multicolumn{2}{|c|}{$\begin{array}{l}\text { Time-loss illnesses per } \\
1000 \text { registered athletes }\end{array}$} \\
\hline & Men & Women & Men & Women & Men & Women & Men & Women & Men & Women \\
\hline \multicolumn{11}{|l|}{ Discipline } \\
\hline $100 \mathrm{~m}$ & 75 & 74 & 4 & 5 & 0 & 1 & 53.3 & 67.6 & 0 & 13.5 \\
\hline $200 \mathrm{~m}$ & 55 & 41 & 7 & 1 & 1 & 0 & 127.3 & 24.4 & 18.2 & 0 \\
\hline $400 \mathrm{~m}$ & 41 & 38 & 4 & 3 & 1 & 1 & 97.6 & 78.9 & 24.4 & 26.3 \\
\hline $800 \mathrm{~m}$ & 44 & 36 & 0 & 3 & 0 & 1 & 0.0 & 83.3 & 0 & 27.8 \\
\hline $4 \times 100$ m relay & 118 & 111 & 2 & 3 & 2 & 0 & 16.9 & 27.0 & 16.9 & 0 \\
\hline $4 \times 400 \mathrm{~m}$ relay & 87 & 100 & 10 & 1 & 0 & 0 & 114.9 & 10.0 & 0 & 0 \\
\hline $110 \mathrm{~m} / 100 \mathrm{~m}$ hurdles & 32 & 39 & 1 & 4 & 0 & 1 & 31.3 & 102.6 & 0 & 25.6 \\
\hline $400 \mathrm{~m}$ hurdles & 34 & 38 & 2 & 4 & 1 & 1 & 58.8 & 105.3 & 29.4 & 26.3 \\
\hline $1500 \mathrm{~m}$ & 39 & 35 & 4 & 1 & 2 & 1 & 102.6 & 28.6 & 51.3 & 28.6 \\
\hline $3000 \mathrm{~m}$ & 35 & 33 & 1 & 1 & 0 & 0 & 28.6 & 30.3 & 0 & 0 \\
\hline $5000 \mathrm{~m}$ & 41 & 24 & 3 & 0 & 0 & 0 & 73.2 & 0 & 0 & 0 \\
\hline $10000 \mathrm{~m}$ & 21 & 19 & 1 & 2 & 0 & 0 & 47.6 & 105.3 & 0 & 0 \\
\hline Marathon & 68 & 56 & 6 & 8 & 0 & 2 & 88.2 & 142.9 & 0 & 35.7 \\
\hline 20 km walk & 47 & 50 & 2 & 8 & 0 & 2 & 42.6 & 160.0 & 0 & 40.0 \\
\hline 50 km walk & 46 & - & 7 & - & 2 & 0 & 152.2 & - & 43.5 & - \\
\hline Discus throw & 33 & 24 & 1 & 1 & 0 & 0 & 30.3 & 41.7 & 0 & 0 \\
\hline Hammer throw & 35 & 30 & 2 & 2 & 0 & 1 & 57.1 & 66.7 & 0 & 33.3 \\
\hline Javelin throw & 37 & 28 & 4 & 2 & 2 & 1 & 108.1 & 71.4 & 54.1 & 35.7 \\
\hline Shot put & 28 & 25 & 0 & 2 & 0 & 0 & 0 & 80.0 & 0 & 0 \\
\hline High jump & 19 & 29 & 2 & 3 & 0 & 0 & 105.3 & 103.4 & 0 & 0 \\
\hline Pole vault & 29 & 35 & 0 & 2 & 0 & 0 & 0 & 57.1 & 0 & 0 \\
\hline Long jump & 37 & 36 & 2 & 3 & 0 & 0 & 54.1 & 83.3 & 0 & 0 \\
\hline Triple jump & 32 & 34 & 1 & 0 & 0 & 0 & 31.3 & 0 & 0 & 0 \\
\hline Decathlon & 30 & - & 0 & - & 0 & - & 0 & - & 0 & - \\
\hline \multirow[t]{2}{*}{ Heptathlon } & - & 29 & - & 1 & - & 0 & - & 34.5 & - & 0 \\
\hline & & & & & & & 53.3 & 67.6 & & \\
\hline Total* & 1063 & 964 & 66 & 60 & 11 & 12 & 127.3 & 24.4 & 10.3 & 12.4 \\
\hline
\end{tabular}

* Since some athletes competed in more than one discipline, this is not the sum of individual athletes.

distinguish between anterior and posterior thigh injuries. Specific studies have suggested that hamstring mechanics during sprint, ${ }^{18}$ strength imbalances, ${ }^{19}$ flexibility, fatigue, age, ethnicity (particular racial or anatomical predisposition) and severity of previous injury ${ }^{20}$ play a role in occurrence of track and field hamstring strain. ${ }^{21}$ However, the exact biomechanics and contribution of hamstring during sprint remain unknown and is debated. ${ }^{21}$ Indeed, a recent publication advocates that hamstring peak force occurs in the stride cycle during terminal swing which suggests a focus on hamstring strengthening exercises, especially involving eccentric contractions performed with high loads at long muscle-tendon lengths. ${ }^{18}$ However, since hamstring and opposing forces are higher in early stance than in late swing, concentric contractions in close chain with high loads could also be of interest. $^{22}$ The quick change in the contraction mode (eccentric to concentric) with a concomitant significant increase in hamstring applied forces may represent a stage of fragility during the sprinting cycle. Further studies on hamstring strains, such as in team sports, ${ }^{23-25}$ should be a priority of track and field injury-prevention research to better understanding the mechanisms and risk factors in order to determine and evaluate the efficacy of adapted prevention measures. Other main injuries were lower leg strain (5-9\%), ankle sprain (3-6\%) and trunk muscle cramps $(6 \%),{ }^{12}$ and in agreement with previous studies, the majority of injuries were caused by overuse. ${ }^{1}$ 21326 Thus, appropriate prevention strategies for overuse injuries should also be implemented including the recording of overuse injuries throughout the season to better determine the overuse injury prevalence, ${ }^{27}$ precociously treating acute injuries, eliminating periods of overtraining and improving preventive strengthening and recovery programs. No concussion or anterior cruciate ligament ruptures were reported in contrast with other sports where these major time-loss injuries are frequent. ${ }^{35}$

\section{Incidence and diagnosis of illnesses}

The incidence of illnesses during the Daegu 2011 Champi- $^{-}$ onships was equal to that reported during the Berlin 2009 Championships $^{2}$ (7.6 injuries per 1000 athlete days). This rate is also similar to those reported in other international sport events. 589

The distribution of affected systems, main symptoms and causes was similar between the Daegu 2011 and Berlin 2009 Championships. $^{2}$ Athletes performing in race walking presented a higher incidence of illness, as was reported during the Berlin 2009 Championships. ${ }^{2}$ During elite Athletics Championships, around $35 \%-38 \%$ of illnesses affected the upper respiratory tract and $15 \%$ the gastrointestinal system. Around $30 \%$ of illnesses lead to pain, $10 \%$ to diarrhoea/ vomiting and $10 \%$ to fever and around $30 \%$ of illnesses were caused by infection, while $20 \%-30 \%$ were exercise induced. Surprisingly, our results reported only $1.5 \%$ of illnesses from 
cardiovascular system illnesses compared with $22.2 \%$ during Berlin $2009 .^{2}$ This difference could be explained by the difficulty of physicians to record systemic pathologies (dehydration, for example), and by the fact that $19 \%$ of illness affected system were classified as 'other' in the present study. However, only one cardiovascular-related collapse was reported during Daegu 2011 versus seven during Berlin 2009, ${ }^{2}$ possibly due to the implementation of prevention strategies. Dehydration was higher during Daegu 2011 (10\% of symptoms) most likely related to weather conditions. Preventive measures should be implemented in further Championships with similar climatic circumstances.

The most common diagnosis was upper respiratory tract infection, in agreement with the Berlin 2009 results, but with a lower rate $\left(18.4 \%\right.$ vs $30.4 \%$, respectively). ${ }^{2}$ These findings are consistent with data from other elite sporting events. 2589 Indeed, upper respiratory tract infections are more common in elite athletes than in non-competitive athletes. ${ }^{28} 29$ The addition of stress and the intensity of competition could explain this high rate of upper respiratory tract infections. Temperature and humidity changes between athletes' accommodation, outdoor, warm-up area, call room or stadium could also play a role. Gastroenteritis and dehydration were also commonly reported during elite Athletics Championships (around 10\% and $12 \%-17 \%$, respectively). ${ }^{2}$ Climatic conditions, nutritional changes, overcrowding and high intensity of activity could be predisposing factors.

\section{Limitations and perspectives}

Methodological limitations have been previously discussed, ${ }^{3} 4$ however, some limitations of our study should be mentioned. First, concerning the cause of injury, potential difficulties or mistakes could have been reported by physicians between acute and chronic injuries. Indeed, in the present study, $77 \%$ of hamstring strains were caused by overuse $(20.5 \%$ by gradual and $56.5 \%$ by sudden onset). This rate is unexpectedly high for this pathology which is most often reported as acute. 1930 'Sudden onset' could have been interpreted as 'acute' by physicians, or athletes could have presented previous symptoms. Second, new injuries, recurrence of previous injury (or reinjury) or injury aggravation (or exacerbation) are difficult to distinguish. ${ }^{31}$ In this context, to improve the collection data system by adding items such as 'acute or overuse injury', 'new injury, reinjury or exacerbation'12 and 'right or left side'11 could be relevant. A third observation is that $20 \%$ to $30 \%$ of affected systems, main symptoms and causes of illnesses were reported as 'other', which highlights the collection data system limitations in describing illnesses. The coding system could be improved to allow physicians to report illnesses more accurately. Finally, since almost $20 \%-30 \%$ of injuries and illnesses were not reported by the team physicians, the daily report from team physicians could be not complete. Thus, other tools (retrospective interview of athletes, media monitoring or web-based system) should be used to improve the accuracy of the data. ${ }^{11} 12$

\section{Injury- and illness-prevention strategies in elite track and field athletes}

Since overuse is the main cause of elite track and field injuries, future studies during IAAF World Championships should also include pre-existing (chronic) injuries and a history of injuries in order to better determine the part of newly occurred, aggravation, recurrence of previous or chronic injuries, and also to help determine risk factors. A periodic health examination and an appropriate methodology for recording overuse symptoms would also help physicians to determine the potential deficiency, risk factors and/ or chronic injuries or illnesses in order to introduce prevention strategies before world events and before injury or illness incurred. 2732

Further studies should focus on the main common injuries in order to better understand the mechanisms and risk factors before introducing prevention measures, ${ }^{67}$ especially regarding hamstring strains. ${ }^{18-21}$

In order to prevent respiratory tract infections, gastroenteritis and dehydration, education of athletes and their entourage on infectious disease and dehydration prevention strategies is necessary. ${ }^{5}$ Athletes should be advised to seek shade and to hydrate regularly, to drink only bottled water, to eat safe food and to employ regular hand washing with alcohol gel. The use of plastic to cover carpeted hotel rooms, and special indoor air cleaning systems, along with discouraging hand shaking and close contact with people outside the team, including fans and the media, should also decrease illness transmission. ${ }^{5} 1033$ Screening tests on airway problems and adapted strategies for athletes with a heavy competition load should be offered to all athletes at risk. ${ }^{10}$

\section{CONCLUSION}

The injury and illness surveillance system proved again to be accepted by the team physicians and feasible in individual sport competition. However, further efforts should be implemented in the future to improve data completeness and quality. During elite Athletics World Championships, 135 injuries, 60 time-loss injuries and 68 illnesses per 1000 registered athletes were reported. Athletes competing in combined events and long-distance runs have the highest injury risk. Preventive interventions should focus on overuse injuries, hamstring strains and adequate rehabilitation of previous injuries, and decreasing the risk of transmission of infectious diseases, appropriate event scheduling and heat acclimatisation.

Acknowledgement The authors highly appreciate the cooperation of the team physicians and the medical staff of the IAAF World Championships who volunteered their time to collect the data for this project. The authors would like to gratefully acknowledge the commitment and enthusiasm of Ms Jeong, Ms Kim, Mr Jeong, Ms Lee and Dr Lee.

Contributors Juan-Manuel Alonso, MD, PhD: first author, substantial contributions to conception and design, acquisition, analysis and interpretation of data; drafting the article and revising it critically for important intellectual content; and final approval of the version to be published. Pascal Edouard, MD, PhD: second author, substantial contributions to conception and design, acquisition of data, analysis and interpretation of data; drafting the article and revising it critically for important intellectual content; and final approval of the version to be published. Giuseppe Fischetto, MD: substantial contributions to acquisition of data, revising it critically for important intellectual content; and final approval of the version to be published. Bob Adams, DO: substantial contributions to acquisition of data, revising it critically for important intellectual content; and final approval of the version to be published. Frédéric Depiesse, MD: substantial contributions to acquisition of data, revising it critically for important intellectual content; and final approval of the version to be published. Margo Mountjoy, MD: last author, Critical revision of intellectual content; English standardisation of manuscript and final approval of the version to be published.

Competing interests None.

Ethics approval Oslo University School of Medicine Ethical Committee.

Provenance and peer review Not commissioned; externally peer reviewed. 


\section{What is already known on this topic}

- The incidence of injuries was 97 and 135.4 per 1000 registered athletes during the 2007 and 2009 IAAF World Championships, respectively; and the incidence of illnesses was 68.2 per 1000 registered athletes during the 2009 IAAF World Championships.

- Most injuries were caused by overuse.

- The most common injury was thigh strain and the most common illness was upper respiratory tract infection.

\section{What this study adds}

- During elite track and field world Championships, incidences are 135 injuries, 60 time-loss injuries and 68 illnesses per 1000 registered athletes.

- Most frequent diagnoses of injury and time-loss injury are thigh strain (and especially hamstring strain), followed by ankle sprain, trunk muscle cramps and lower leg strain.

- The most common diagnoses were upper respiratory tract infection, gastroenteritis and dehydration.

\section{REFERENCES}

1. Alonso JM, Junge A, Renstrom P, et al. Sports injuries surveillance during the 2007 IAAF World Athletics Championships. Clin J Sport Med 2009;19:26-32.

2. Alonso JM, Tscholl PM, Engebretsen L, et al. Occurrence of injuries and illnesses during the 2009 IAAF World Athletics Championships. Br J Sports Med 2010;44:1100-5

3. Junge A, Engebretsen L, Mountjoy ML, et al. Sports injuries during the Summer Olympic Games 2008. Am J Sports Med 2009;37:2165-72.

4. Junge A, Engebretsen L, Alonso JM, et al. Injury surveillance in multi-sport events: the International Olympic Committee approach. Br J Sports Med 2008; 42: 413-21.

5. Engebretsen L, Steffen K, Alonso JM, et al. Sports injuries and illnesses during the Winter Olympic Games 2010. Br J Sports Med 2010;44:772-80.

6. van Mechelen W, Hlobil H, Kemper HC. Incidence, severity, aetiology and prevention of sports injuries. A review of concepts. Sports Med 1992;14:82-99.

7. Bahr R, Krosshaug T. Understanding injury mechanisms: a key component of preventing injuries in sport. Br J Sports Med 2005;39:324-9.

8. Dvorak J, Junge A, Derman W, et al. Injuries and illnesses of football players during the 2010 FIFA World Cup. Br J Sports Med 2011;45:626-30.

9. Mountjoy M, Junge A, Alonso JM, et al. Sports injuries and illnesses in the 2009 FINA World Championships (Aquatics). Br J Sports Med 2010;44:522-7.
10. Hanstad DV, Rønsen 0, Andersen SS, et al. Fit for the fight? Illnesses in the Norwegian team in the Vancouver Olympic Games. Br J Sports Med 2011;45:571-5.

11. Flørenes TW, Nordsletten L, Heir S, et al. Recording injuries among World Cup skiers and snowboarders: a methodological study. Scand J Med Sci Sports 2011;21:196-205.

12. Bjørneboe J, Flørenes TW, Bahr R, et al. Injury surveillance in male professional football; is medical staff reporting complete and accurate? Scand J Med Sci Sports 2011;21:713-20.

13. Edouard P, Morel N, Serra J-M, et al. [Prevention of musculoskeletal injuries in track and field. Review of epidemiological data]. Sci Sports 2011;26:307-15.

14. Rebella GS, Edwards J0, Greene $\mathrm{JJ}$, et al. A prospective study of injury patterns in high school pole vaulters. Am J Sports Med 2008;36:913-20.

15. Edouard P, Samozino P, Escudier G, et al. Injuries in youth and national combined events championships. Int J Sports Med (In Press).

16. Edouard P, Pruvost J, Edouard JL, et al. Causes of dropouts in decathlon. A pilot study. Phys Ther Sport 2010;11:133-5.

17. Mayr B, Paar O, Bernett P, et al. [Sports injuries and sports damage in decathlon competitors]. Schweiz Z Sportmed 1988;36:39-45.

18. Schache AG, Dorn TW, Blanch PD, et al. Mechanics of the Human Hamstring Muscles during Sprinting. Med Sci Sports Exerc 2012;44:647-58.

19. Yeung SS, Suen AM, Yeung EW. A prospective cohort study of hamstring injuries in competitive sprinters: preseason muscle imbalance as a possible risk factor. Br J Sports Med 2009;43:589-94.

20. Malliaropoulos N, Isinkaye T, Tsitas K, et al. Reinjury after acute posterior thigh muscle injuries in elite track and field athletes. Am J Sports Med 2011;39:304-10.

21. Opar DA, Williams MD, Shield AJ. Hamstring strain injuries: factors that lead to injury and re-injury. Sports Med 2012;42:209-26.

22. Orchard JW. Hamstrings are most susceptible to injury during the early stance phase of sprinting. Br J Sports Med 2012;46:88-9.

23. Ekstrand $\mathbf{J}$, Hägglund $\mathrm{M}$, Waldén $\mathrm{M}$. Epidemiology of muscle injuries in professional football (soccer). Am J Sports Med 2011;39:1226-32.

24. Croisier JL, Ganteaume S, Binet J, et al. Strength imbalances and prevention of hamstring injury in professional soccer players: a prospective study. Am J Sports Med 2008:36:1469-75.

25. Arnason A, Andersen TE, Holme l, et al. Prevention of hamstring strains in elite soccer: an intervention study. Scand J Med Sci Sports 2008;18:40-8.

26. Jacobsson J, Timpka T, Kowalski J, et al. Prevalence of musculoskeletal injuries in Swedish elite track and field athletes. Am J Sports Med 2012;40:163-9.

27. Bahr R. No injuries, but plenty of pain? On the methodology for recording overuse symptoms in sports. Br J Sports Med 2009;43:966-72.

28. Spence L, Brown WJ, Pyne DB, et al. Incidence, etiology, and symptomatology of upper respiratory illness in elite athletes. Med Sci Sports Exerc 2007;39:577-86.

29. Bermon S. Airway inflammation and upper respiratory tract infection in athletes: is there a link? Exerc Immunol Rev 2007;13:6-14.

30. Malliaropoulos N, Papacostas E, Kiritsi O, et al. Posterior thigh muscle injuries in elite track and field athletes. Am J Sports Med 2010;38:1813-19.

31. Fuller CW, Bahr R, Dick RW, et al. A framework for recording recurrences, reinjuries, and exacerbations in injury surveillance. Clin J Sport Med 2007;17:197-200.

32. Ljungqvist $\mathbf{A}$, Jenoure $P$, Engebretsen $L$, et al. The International Olympic Committee (IOC) Consensus Statement on periodic health evaluation of elite athletes March 2009. Br J Sports Med 2009;43:631-43.

33. Tillett $\mathbf{E}$, Loosemore M. Setting standards for the prevention and management of travellers' diarrhoea in elite athletes: an audit of one team during the Youth Commonwealth Games in India. Br J Sports Med 2009;43:1045-8. 